\title{
Finite Element Analysis on Rubber Sealing Ring of the Rotary Liner Hanger Bearing
}

\author{
Weiqing $\mathrm{Li}^{*}$, Yu Wang and Detian Miao \\ School of Engineering and Technology \\ China University of Geosciences (Beijing) \\ Beijing, China \\ *Corresponding author
}

\begin{abstract}
Rotary liner hanger bearing will be wear sharply and decreased its service life if the sealing structure is not able to prevent the drilling fluid to enter into the bearing. A twodimensional finite element model of the self-designed nonstandard rubber sealing ring was carried out on the software of ABAQUS. The rules of deformation and stress for the sealing ring with different value of initial interference, working pressure and the deep-well temperature were studied. The result shows that the maximum contact stress increases with the increase of value of initial interference and the maximum contact stress is always bigger than the value of work pressure. The effect of deepwell high temperature on sealing performance is not obvious compared with normal temperature. The result of this study is able to be the basis of modifying the structure and improving the performance of sealing ring.
\end{abstract}

Keywords-rubber sealing ring; non-linear finite element analysis; contact stress; sealing performance; thermo-mechanical coupling

\section{INTRODUCTION}

Rotary liner hanger bearing working in a high temperature, high pressure and mud environment has special requirements on sealing ring. Bearing system will wear sharply and decrease the quality and service life of the rotary liner hanger once the sealing structure cannot prevent the mud into the bearing [1]. Aliterature reported that about 15,000 oil and gas wells are not able to work well because of the quality of rotary liner hanger each year in China. So the performance of sealing ring is very important [2].

In this paper, the rotary liner hanger bearing is designed to be lip rubber sealing ring. The lip sealing ring which has complex geometry and nonlinear material property must meet the requirements on deep-well temperature. Not only theoretical data or application experience but also the relevant literature and the cost of expensive experiments are the primary difficulties. With the aid of the software of the non-linear finite element ABAQUS, this paper simulated and obtained the result of the performance of sealing ring used in rotary liner hanger bearing by analyzing the maximum contact stress and deformation variation with different initial interference, working pressure and the deep-well temperature. The analysis results could provide the related reference on the bearing and seal design.

\section{ANALYSIS MODEL OF RUBBER SEAL RING}

\section{A. Rotary liner Hanger Bearing and Its Sealing Ring Structure}

In order to meet the requirements of the axial load $(\geqslant$ 60tons) bearing capacity and service life ( $\geqslant 20$ hours $)$ of the bearing in the working process, a full loaded thrust tapered roller bearing is designed. Its main structures include upper just ring, outer sealing ring, retaining ring, lower just ring, outer sealing ring, inner sealing ring, seat ring, roller, axial ring, and inner sealing ring. The overall structural model of the bearing is shown in Figure I.

Part 5 and part10 are respectively inside and outside sealing ring. The main structure and size of the sealing ring is shown in Figure II.

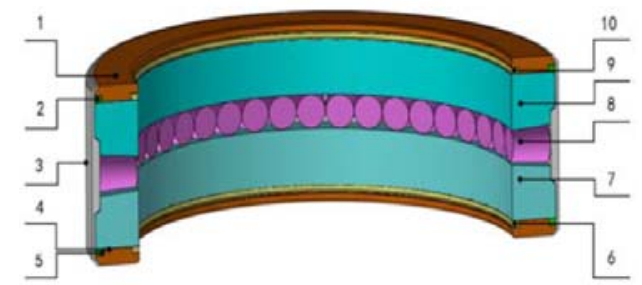

1-Upper just ring 2-Outer sealing ring 1 3-Retaining ring 4-Lower just ring 5-Outer sealing ring 6- Inner sealing ring 1 7-Seat ring 8-Roller 9-Axial ring 10-Inner sealing ring 2

FIGURE I STRUCTURE OF BEARING FOR HUNGER

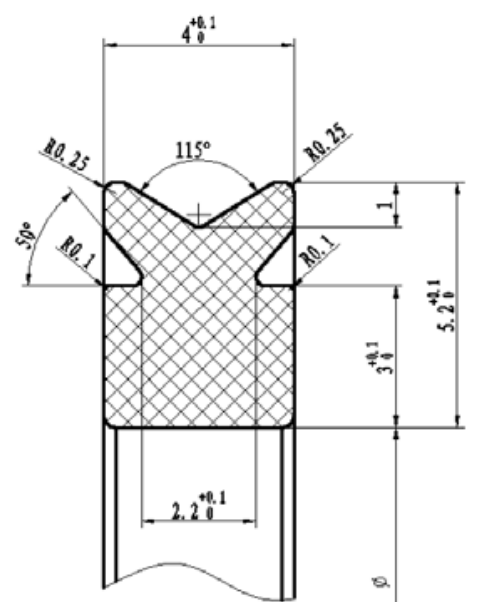

FIGURE II STRUCTURE OF THE SEAL RING 


\section{B. Finite Element Model}

The nonlinearities of rubber sealing ring include three aspects of material, contact and geometry, which increase the difficulty of analysis. In order to make the calculations feasible and satisfactory with actual working conditions, the hypotheses are as follows:

a) The lip sealing ring model belongs to the axial symmetry stress analysis due to the symmetry of the bearing seal structure and its loading.

b) Simplifying the sealing ring $3 \mathrm{D}$ model as the twodimensional model on the basis of the rubber sealing ring geometry, loading ways and the boundary condition.

c) The sealing groove and retaining ring are the rigid boundary because their stiffness is tens of thousands of times higher than the rubber. The rubber sealing ring material is incompressible one.

As is showed in the Figure I, the outer sealing structure is the same as inner one, so they have the same sealing performance. This paper only took the out sealing structure for example to simulate the sealing performance of rotary liner hanger bearing.

The structure of rotary liner hanger bearing is mainly composed of shaft washer, seat ring, retaining ring and rubber sealing ring in the sealing groove. This paper focuses on carrying on the static analysis of the sealing ring. In order to save computer resources, this paper only make an analysis on the rubber sealing ring and its surrounding rigid parts but omit other bearing rigid structures, which is able to keep the function integrity of the bearing sealing structure and simplify the analysis model. The simplified model is shown in Figure III.

The material parameters are shown in Table I. The material of sealing ring is fluorine rubber. Its $\mathrm{C} 10$ is 2. 2and $\mathrm{C} 01$ is $0.57[3]$.

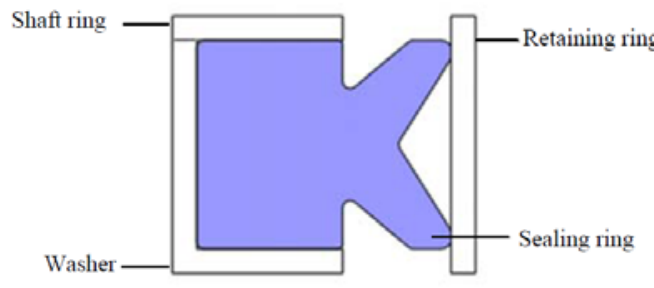

FIGURE III SIMPLIFIED MODEL

TABLE I MATERIAL PARAMETERS

\begin{tabular}{|c|c|c|c|}
\hline Parts & Materials & $\begin{array}{c}\text { Young modulus } \\
(\mathrm{GPa})\end{array}$ & Poisson ratio \\
\hline Sealing ring & Fluorine rubber & - & 0.49 \\
\hline Shaft ring & Military armour steel & 206 & 0.3 \\
\hline Seat ring & Military armour steel & 206 & 0.3 \\
\hline Washer & 45 steel & 206 & 0.3 \\
\hline $\begin{array}{c}\text { Retaining } \\
\text { ring }\end{array}$ & $20 \mathrm{CrMnTi}$ & 206 & 0.3 \\
\hline
\end{tabular}

This paper set the mesh density by the method of scattering seeds. The rigid parts adopt the technology of free mesh division. Lip sealing ring use hybrid element mesh CAX4H.

\section{SimUlation ANALYSIS}

Two steps of loading calculations are carried out in the simulation analysis in order to simulate the actual working conditions.

In the first step, an initial displacement of the retaining ring to the left is given to make the rubber sealing ring reach the pre- tightening state. In the second step, working pressure is added to the lip position of the rubber sealing ring to simulate fluid pressure of drilling fluid during the process of the rotary liner hanger entering a well. According to the deep-well pressure, the load in this paper ranges from 0 to $11 \mathrm{Mpa}$ [4].

Boundary conditions and loading method: The axial displacement of the retaining ring is defined as 0 . The initial interference is expressed by applying a certain amount of retaining ring displacement along horizontal direction. The displacements of sealing groove which is composed of shaft ring and washer are defined as 0in the vertical and horizontal direction of the sealing groove.

The set of contact: Because the material of the ring is steel and the material of the sealing ring is a rubber, their contact property is defined as rigid-flexible contact. Two contact pairs are built between retaining ring and rubber sealing ring. Three contact pairs are built between rubber sealing ring and sealing groove and their contact property is defined as rigid-flexible contact. The rigid body belongs to the main surface, and rubber sealing ring belongs to the subordinate surface.

\section{CALCUlation Results AND ANALYSis}

By using ABAQUS, this paper focuses on the changing rule of sealing ring in deformation, Von Mises stress and contact stress under different initial interference, working pressure and temperature conditions.

The maximum contact stress is the reflection of the sealing performance of the sealing ring. The necessary sealing condition is that the maximum contact stress is bigger than or equal to the working medium pressure[5,6].

Von Mises stress is a reflection of the stress concentration situation. Generally speaking, the stress relaxation of the super elastic body material and the region of the crack are often the site where Von Mises stress value is much bigger[7]. The greater the Von Mises stress of sealing ring increases, the easier the sealing ring is more prone to stress relaxation or cracks[8].

General expression for Von Mises stress is(1)

$$
\sigma=\sqrt{\frac{1}{2}\left[\left(\sigma_{1}-\sigma_{2}\right)^{2}+\left(\sigma_{2}-\sigma_{3}\right)^{2}+\left(\sigma_{3}-\sigma_{1}\right)^{2}\right]}
$$

Where, $\sigma_{1}, \sigma_{2}$ and $\sigma_{3}$ are respectively the first principal stress, the second principal stress and the third principal stress.

\section{A. Simulation of Differentinitial Interference}

The initial interference is an important parameter in the sealing performance. TOO small interference is easy to cause 
leakage, which will reduce the sealing performance. But too large initial interference will cause excessive friction, which will increase the wear and tear, and reduce the service life of the sealing ring. Therefore, it is very important to choose the appropriate amount of interference in the sealing performance of the sealing ring. In order to study the effect of the initial interference on the sealing performance, the stress and strain of the working pressure at zero is firstly studied. Figure IV and Figure $\mathrm{V}$ are the analysis results of the sealing ring contact stress and Von Mises stress when working pressure is zero.

The peak area of Von Mises stress in the sealing ring is approximately the same. Figure IV show that the maximum Von Mises stress is mainly concentrated at the mouth of the sealing ring. This indicates that the crack is the most likely to appear in the mouth under different working pressures[9].Figure $\mathrm{V}$ shows that the maximum contact stress occurs in the place of the contact area between the sealing ring and the retaining ring, which is required by the seal because the contact stress is conducive to improve the sealing performance.

When the working pressure is zero and $0.1 \mathrm{~mm}, 0.3 \mathrm{~mm}$, $0.5 \mathrm{~mm}$, and $0.7 \mathrm{~mm}$ are taken as the initial value of interference, Table II is the results of the maximum contact between the retaining ring and the sealing ring, maximum Von Mises stress and maximum deformation with different of the initial interference.

Table II show that Von Mises stress increases with the increase of the initial interference. So the initial interference should not be too large.

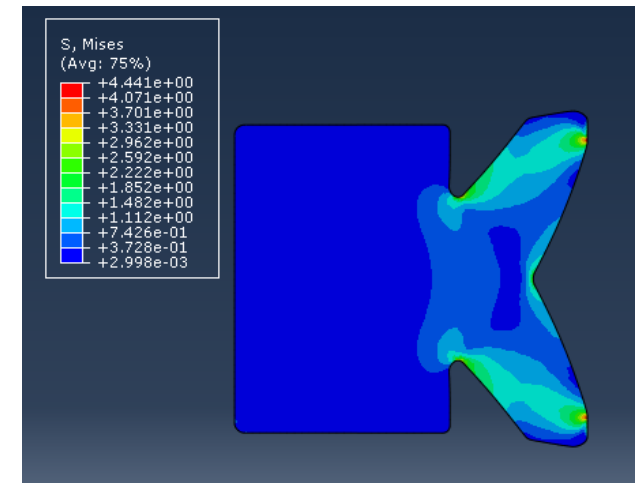

FIGURE IV DISTRIBUTION OF SEAL RING VON MISES STRESS $\quad(\mathrm{F}=0, \mathrm{e}=0.3 \mathrm{~mm})$

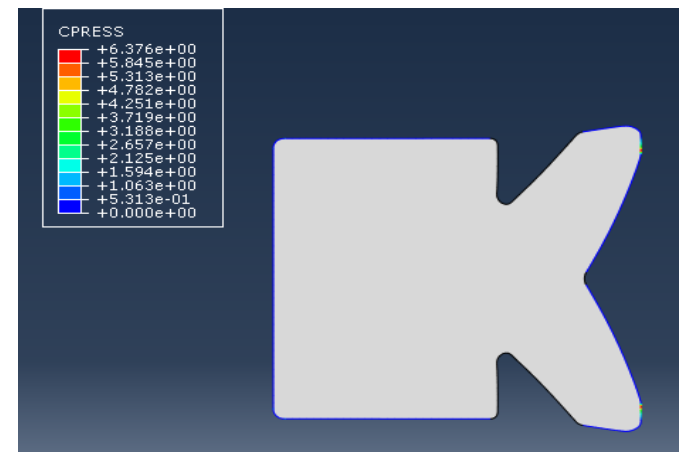

FIGURE V DISTRIBUTION OF SEALING RING CONTACT STRESS $(\mathrm{F}=0, \mathrm{e}=0.3 \mathrm{~mm})$
TABLE II THE CHANGES OF CONTACT STRESS, VON MISES STRESS AND DEFORMATION WITH INITIAL INTERFERENCE $(\mathrm{F}=0)$

\begin{tabular}{|l|l|l|l|l|}
\hline Magnitude & of & interference & & \\
\hline$(\mathrm{mm})$ & 0.1 & 0.3 & 0.5 & 0.7 \\
\hline Maximum & contact & stress & $(\mathrm{Mpa})$ & 3.070 \\
\hline Maximum & deformation $(\mathrm{mm})$ & 0.114 & 0.368 & 0.632 \\
\hline
\end{tabular}

With the increase of the initial interference, the maximum contact stress of the sealing ring increase. The growth trend is obvious at the beginning, and it reached the peak value when the interference is $0.5 \mathrm{~mm}$. Then, the maximum contact stress of the sealing ring slowly decreased and the variation amplitude decreases as the interference continues to increase. The reason is, with the increase of the initial interference, the contact width of lip and retaining ring is increasing. When the width reaches a certain value, contact width variation is smaller.

Table II also shows that, with the increase of the initial interference, the deformation of the seal ring lip increase obviously at the beginning, and the contact width also increased. Continue to increase the interference, the deformation of the sealing ring is no longer significant. This is determined by the geometry of the sealing ring and its ability to resist deformation.

According to the above analysis, the structure of the sealing ring can resist excessive deformation, which indicates that its structure is basically reasonable. If the contact stress and Von Mises stress varying are taken into account, this paper argues that $0.3 \mathrm{~mm}$ is an appropriate initial interference.

\section{B. Simulation of Different Working Pressure}

According to the above, analysis of this part is based on the initial interference of $0.3 \mathrm{~mm}$ and working pressure in the range of 1-11Mpa.

Figure VI shows the change of maximum contact stress and maximum Von Mises stress with different working pressure. It shows that the maximum contact stress and the maximum Von Mises stress increase with the increase of working pressure.

Figure VI also shows that the maximum contact pressure is always bigger than the working pressure in the range of 1$11 \mathrm{Mpa}$, which shows that the sealing ring has a good sealing performance that can meet the needs of deep well drilling.

\section{Simulation of Thermo-mechanical Coupling}

The rotary liner hanger bearing is operated in high temperature and high pressure environment. Besides the medium pressure, the bearing also needs to withstand the test of high temperature. Study on coupling of high temperature and high pressure is able to provide a theoretical basis for the design and optimization of sealing components of down hole drilling tools[10].

This paper applied the sequential coupling method. Firstly, the thermal stress was analyzed. Then, the working load was loaded on the result of analysis of thermal stress.

Table III show the maximum deformation, maximum contact stress and maximum Von Mises stress when the temperature load is respectively $25^{\circ} \mathrm{C}, 120^{\circ} \mathrm{C}, 130^{\circ} \mathrm{C}, 140^{\circ} \mathrm{C}$ 
and $150{ }^{\circ} \mathrm{C}$. The results are on condition that the initial interference is $0.3 \mathrm{~mm}$ and the working pressure is $7 \mathrm{MPa}$.

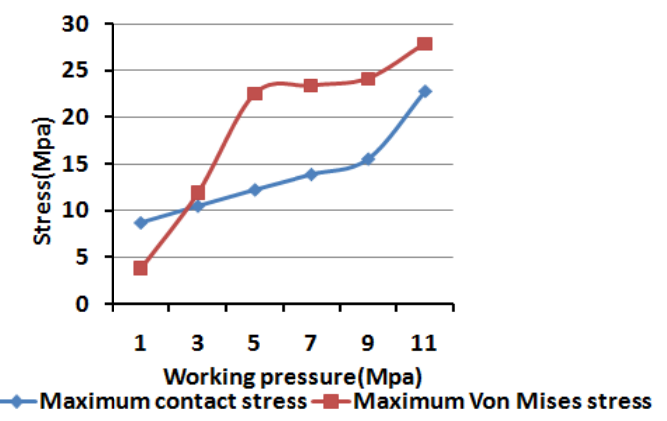

FIGURE VI FVARIETIONS OF MAXIMUM CONTACT STRESS AND MAXIMUM VON MISE STRESS WITH WORKING PRESSURE TABLE III THE CHANGE OF DEFORMATION, CONTACT
STRESS AND VON MISES STRESS AT DIFFERENT TEMPERATURE $(\mathrm{F}=7 \mathrm{MPA}, \mathrm{E}=0.3 \mathrm{MM})$

\begin{tabular}{|c|c|c|c|}
\hline $\begin{array}{c}\text { Temperatur } \\
\mathbf{e}\left({ }^{\circ} \mathrm{C}\right)\end{array}$ & $\begin{array}{c}\text { Deformatio } \\
\mathbf{n}(\mathbf{m m})\end{array}$ & $\begin{array}{c}\text { Maximum contact } \\
\text { stress (Mpa) }\end{array}$ & $\begin{array}{c}\text { Maximum Von Mises } \\
\text { stress (Mpa) }\end{array}$ \\
\hline 25 & 0.427 & 14.33 & 23.14 \\
\hline 120 & 0.390 & 14.27 & 23.21 \\
\hline 130 & 0.395 & 14.38 & 23.22 \\
\hline 140 & 0.400 & 14.48 & 23.28 \\
\hline 150 & 0.403 & 14.59 & 23.23 \\
\hline
\end{tabular}

The increase of maximum Von Mises stress of rubber sealing ring and maximum contact stress of deep-well temperature was not obvious compared with the value of $25^{\circ} \mathrm{C}$.It is concluded that the increase of temperature has little effect on the sealing performance of the bearing. The structure and the material of the sealing ring can meet the conditions of high temperature.

\section{CONCLUSION}

With the aid of the software of ABAQUS, nonlinear FEM Contact Model of self-designed lip sealing ring is realized. These simulated results provide the basis for rotary liner hanger bearing sealing ring design and optimization. The simulation method could cut test cost, increase test efficiency.

a) The maximum contact stress increases with the increase of initial interference. The contact stress is always bigger than working pressure with the action of different work pressures, which ensure the sealing performance of rubber seal ring.

b) The maximum Von Mises stress and deformation gradually enlarged with the increases of working pressure, which shows that the probability of the relaxation and crack will increase with the increases of working pressure.

c) The stress distributions are obtained by the simulating with FEM. The failure zone can be estimated efficiently

d) The effect of deep-well high temperature on sealing performance is not obvious compared with normal temperature.
The structure and the material of the sealing ring in this paper is able to meet the conditions of high temperature.

\section{ACKNOWLEDGMENT}

This project was supported by the Fundamental Research Funds for the Central Universities (265201304). This project also thanks Luoyang Bearing Science \& Technology Co., Ltd who provide us with test data so that we have the reference of the simulation research.

\section{REFERENCES}

[1] Weiqing Li, Jianchong Wang, "Analysis of Thermo-Mechanical Coupling Characteristics and Structural Design of Rotary Liner Hanger Bearing in Ultra-Deep Well Drilling," Proceedings of IMETI 2014, pp.33-39, July 15-18, 2014[Orlando Florida, USA].

[2] Tao Wei. Evaluation of oil and gas well cementing quality logging[M]. Beijing: Petroleum industry press. 2010

[3] Zhiyu Wang,Anwen Wang. "Determination of mechanics constants of Mooney-Rivlin model by using multilinear regression method," College of Science,Naval Univ.of Engineering, vol.23, No.2, pp.18 -21, 2011.

[4] Xiaomei Song, Dongzhe Zhang, Yu Wang and XiaoJun Wang. "Improvement of the drilling rotary blowout preventer cooling system," Drilling \& Production Technology, vol.37, No.3, pp.113-114, 2014.

[5] Zhi Chen, $\mathrm{Yu}$ Gao,Rong Dong,Bo Wu and JianMing Li. "Finite Element Analysis of Sealing Characteristics of the Rubber O-Ring for a Mechanical Seal," Journal of Sichuan University(Engineering Science Edition), vol.43, No.5, pp.234-239, 2011.

[6] Wenjin Guan,Qungui Du,Piqun Liu. "Finite Element Analysis of the Sealing Performance of Rubber O-ring," Lubrication Engineering, vol.37, No.6, pp.60-64, 2012.

[7] Min Chen,Xiaomin Jiang,Zuxin Zhao and Xiaobo Huang. "The Nonlinear Contact Finite Element Analysis of the Mouth Shaped Rubber Sealing Ring," Lubrication Engineering, vol.34, No.11, pp.76-79, 2009.

[8] Min Chen, X.M. Jiang, Zu Xin Zhao, and X.B. Huang. "The Non-Linear Contact Finite Element Analysis of Seal Structure on Large Scale Cutting Tube Machine,"Applied Mechanics and Materials,vol.268-270, pp. 1080-1083, 2012.

[9] Xiang Yu Ding, Qiang Yu. "The Influence of Performance of W-Type Metallic Sealing Ring with Different Outer Arms Open Angle," Advanced Materials Research, vol.971 - 973, pp. 806-810, 2014.

[10] Xin Li, Gaoliang Peng, andZhe Li. "Prediction of seal wear with thermal-structural coupled finite element method,"Finite Elements in Analysis \& Design, vol. 83, pp. 10-21, June 2014. 